1 Warwick Clinical Trials Unit, University of Warwick, Coventry, UK

2 University Hospitals of Coventry and Warwickshire, Coventry, UK

Correspondence to: $\mathrm{M}$ Underwood M.Underwood@warwick.ac.uk Cite this as: BMJ 2021;372:n80 http://dx.doi.org/10.1136/bmj.n80 Published: 20 January 2021

\section{Antidepressants for musculoskeletal pain}

\author{
People need help to live better with their pain, without prescription drugs \\ Martin Underwood, ${ }^{1,2}$ Colin Tysall $^{1}$
}

Back pain, neck pain, and osteoarthritis are leading causes of disability globally. ${ }^{1}$ Although non-drug treatments are the preferred first option for such pain and disability, a role remains for drug treatments. ${ }^{23}$ The impact of the opioid prescribing epidemic and the challenges of helping those affected are well known. ${ }^{4}$ Opioid prescribing is decreasing while gabapentinoid use is increasing, despite a weak evidence base and known harms. ${ }^{5}$ The linked paper by Ferreira and colleagues (doi:10.1136/bmj.m4825) reporting a well conducted systematic review of trials of antidepressants for these musculoskeletal disorders is timely. ${ }^{6}$

The authors set a difference of 10 points on a 100 point scale for pain or disability as the smallest worthwhile difference between groups-a threshold commonly used in studies of chronic pain. ${ }^{7}$ It is also the smallest worthwhile individual treatment benefit from non-steroidal anti-inflammatory drugs or physiotherapy for chronic low back pain. ${ }^{8}$ This distinction is important since a modest overall benefit at group level could still mean that a some treated individuals gain a worthwhile benefit. ${ }^{9}$

For back pain, (neck or low back with or without sciatica) pooled data from four industry sponsored trials of duloxetine $(n=1432)$ showed effect sizes substantially smaller than the authors' prespecified worthwhile between group difference. The limits of the reported $95 \%$ confidence intervals effectively excluded any possibility that such an effect size was achieved (mean difference for pain at 3-13 weeks $-5.30,95 \%$ confidence interval -7.31 to -3.30 ). For tricyclic antidepressants, (seven trials, $n=591$ ) the mean difference for pain at 3-13 weeks was -9.9 (95\% confidence interval -21.50 to 1.58 ); although this might not be enough to support the use of these drugs, a worthwhile effect from tricyclic antidepressants has not been excluded. Both findings are consistent with UK National Institute for Health and Care Excellence guidance against the use of antidepressants for low back pain. ${ }^{2}$ The American College of Physicians guidance, however, suggests considering duloxetine as second line drug treatment for chronic low back pain. ${ }^{10}$

It is not possible to draw any conclusions from the limited data (six trials, $n=267$ ) on the use of antidepressants for radicular pain (sciatica). This is of concern when antidepressants might be expected to improve neuropathic pain such as sciatica through central modulation of pain, and when both amitriptyline and duloxetine are recommended by the relevant NICE guidance. ${ }^{11}$ The lack of evidence supporting drugs already widely prescribed for sciatica is perhaps surprising, and more work is needed to confirm or refute the place of these drugs in our armamentarium.

All the osteoarthritis trials included by Ferreira and colleagues tested treatments for knee osteoarthritis; largely industry sponsored studies of duloxetine. Pooled data from eight studies $(n=1941)$ found an effect on pain at 3-13 weeks of -9.72 (95\% confidence interval -12.57 to -6.69 ) meaning that a worthwhile effect has not been excluded. NICE does not make a specific recommendation on antidepressants for osteoarthritis. ${ }^{12}$ Osteoarthritis Research Society International (OARSI) guidance does, however, make a conditional recommendation for the use of duloxetine by people with osteoarthritis and widespread pain or depression. ${ }^{3}$

Making sense of the various sources of evidence and inconsistent recommendations in this area is challenging. For example, draft NICE guidance is to consider antidepressants for chronic pain but not for chronic sciatica. ${ }^{13}$ This problem is common across guidance on other drug groups for chronic painful disorders. ${ }^{14}$ A robust overview is needed to clarify guidance and to inform a consistent approach to use of antidepressants for people with painful disorders. Many people with chronic pain also have symptoms of depression. Any such overview should consider the potential for reducing depressive symptoms

We cannot tell from Ferreira and colleagues' review how many individuals gained a worthwhile benefit from their drug treatment. Despite the reported small effects at group level, some individuals with back pain or osteoarthritis may gain a personal benefit from serotonin-noradrenaline reuptake inhibitors (SNRIs). Absolute effect sizes for physical treatments for low back pain are of similar magnitudes to those reported here and translate into numbers needed to treat of between 5 and 9. ${ }^{9}$ If the same were true for SNRIs, some people might choose to a try that option for a one in 10 chance of a worthwhile reduction in pain after three months. They can easily stop if treatment is ineffective or does not suit them. As others put it: "Expect analgesic failure; pursue analgesic success.” 15

Overall, however, drug treatments are largely ineffective for back pain and osteoarthritis and have the potential for serious harm. We need to work harder to help people with these disorders to live better with their pain without recourse to the prescription pad. ${ }^{14}$

Competing interests: The authors declare the following other interests: $\mathrm{MU}$ is a director and shareholder of Clinvivo, which provides electronic data collection for health services research. He is part of an academic partnership with Serco, funded by the European Social Fund, related to return to work initiatives. He is a co-investigator on three National Institute for Health Research funded studies receiving additional support from Stryker, outside the scope of this editorial. 
The BMJ policy on financial interests is here: https://www.bmj.com/sites/default/files/attachments/resources/2016/03/16-current-bmj-education-coi-form.pdf."

Provenance and peer review: Commissioned; not peer reviewed.

The authors thank Sam Eldable for his comments on an earlier draft.

1 GBD 2017 Disease and Injury Incidence and Prevalence Collaborators. Global, regional, and national incidence, prevalence, and years lived with disability for 354 diseases and injuries for 195 countries and territories, 1990-2017: a systematic analysis for the Global Burden of Disease Study 2017. Lancet2018;392:1789-858. doi: 10.1016/S0140-6736(18)32279-7 pmid: 30496104

2 NICE. Low back pain and sciatica in over 16s: assessment and management. NG59. NICE, 2020.

3 Bannuru RR, Osani MC, Vaysbrot EE, etal. OARSI guidelines for the non-surgical management of knee, hip, and polyarticular osteoarthritis. Osteoarthritis Cartilage 2019;27:1578-89. doi: 10.1016/j.joca.2019.06.011 pmid: 31278997

4 Sandhu H, Underwood M, Furlan AD, Noyes J, Eldabe S. What interventions are effective to taper opioids in patients with chronic pain?BMJ2018;362:k2990.

doi: 10.1136/bmj.k2990 pmid: 30262590

5 Mathieson S, Lin CC, Underwood M, Eldabe S. Pregabalin and gabapentin for pain. BMJ 2020;369:m1315. doi: 10.1136/bmj.m1315 pmid: 32345589

6 Ferreira GE, McLachlan AJ, Lin C-WC, etalEfficacy and safety of antidepressants for the treatment of back pain and osteoarthritis: Systematic review and meta-analysis. 2021;372:m4825.

7 Dworkin RH, Turk DC, Wyrwich KW, etal. Interpreting the clinical importance of treatment outcomes in chronic pain clinical trials: IMMPACT recommendations. J Pain 2008;9:105-21. doi: 10.1016/j.jpain.2007.09.005 pmid: 18055266

8 Ferreira ML, Herbert RD, Ferreira PH, etal. The smallest worthwhile effect of nonsteroidal anti-inflammatory drugs and physiotherapy for chronic low back pain: a benefit-harm trade-off study. J Clin Epidemiol 2013;66:1397-404.pmid: 24021611

9 Froud R, Eldridge S, Lall R, Underwood M. Estimating the number needed to treat from continuous outcomes in randomised controlled trials: methodological challenges and worked example using data from the UK Back Pain Exercise and Manipulation (BEAM) trial. BMC Med Res Methodol 2009;9:35. doi: 10.1186/1471-2288-9-35 pmid: 19519911

10 Chou R, Deyo R, Friedly J, etal. Systemic Pharmacologic Therapies for Low Back Pain: A Systematic Review for an American College of Physicians Clinical Practice Guideline. Ann Intern Med 2017;166:480-92. doi: 10.7326/M16-2458 pmid: 28192790

11 NICE. Neuropathic pain in adults: pharmacological management in non-specialist settings CG173. NICE, 2020

12 NICE. Osteoarthritis: care and management. CG177. NICE, 2020

13 NICE. Guideline: chronic pain in over 16s: assessment and management. Draft for consultation, August 2020. NICE, 2020.

14 Shaheed CA, Machado GC, Underwood M. Drugs for chronic pain. BrJ Gen Pract2020;70:576-7. doi: 10.3399/bjgp20X713549 pmid: 33243903

15 Moore A, Derry S, Eccleston C, Kalso E. Expect analgesic failure; pursue analgesic success. BMJ 2013;346:f2690. doi: 10.1136/bmj.f2690 pmid: 23645858 